intensity of the hydrogen lines has been partially compensated by increased intensity of the nebular lines.

An account of photographs taken at Meudon on June $\mathrm{I}_{2}$ and $\mathrm{I}_{5}$ has been given by Mr. J. Bosler (Comptes rendus, June 24). In addition to the whole series of hydrogen lines, there were bright lines at $592,588,569,532,5^{18}, 502,493$, and 465 , and fainter lines at $648,638,555$, and 454 . The bright lines varied in breadth from 30 to $60 \mathrm{~A}$, and were accompanied by the usual dark lines on their more refrangible sides; if interpreted in terms of motion, the displacements would indicate a relative velocity of $2300 \mathrm{~km}$. per second, or about $2 \frac{1}{2}$ times that observed in any previous nova. Dark lines, apparently without bright companions, occurred at $46 \mathrm{r}, 42 \mathrm{I}, 389$, and $3934(\mathrm{~K})$.

The new line noted by Mr. Phillips on July 4 was about 407 , as in Nova Persei on March 21 and 27 , I90I; the position previously given was erroneous.

Photographs obtained by Mr. Phillips on July I2 and $I_{3}$ show a well-defined line on the red side of $\mathrm{H}_{\gamma}$, which is doubtless the above-mentioned nebular line 4363 . The band at 468 has also been noted in recent plates.

Father Cortie sends the following notes on recent photographs :--." On July I3 a photograph of the spectrum showed that each of the hydrogen bands $\mathrm{H}_{B}$ to $\mathrm{H}_{\zeta}$ contained a central brighter region in which were two bright lines. Each band was about 50 Ângström units in breadth. The bright region at wave-length 4640 extended altogether over 160 angstroms, and consisted of two broad bright bands, in continuous spectrum. On June 30 this bright region had a breadth of go Angström units, and on July 8 of I Io units. There was a second bright band beginning at $\lambda 4523$, and extending over more than 50 units. The visual spectrum showed $\mathrm{H}_{\alpha}$ very bright, and probably just doubled, D bright, and a continuous patch of colour in the green.

"In the photographs of June 29 and 30 the 4640 band was doubled, the more refrangible component being the brighter. The same is true of $\mathrm{H}_{\gamma}$. On July $r_{3}$, in the 4 -in. finder, for a few moments the star itself seemed to be double, the companion just preceding the brighter star in right ascension. This may be an illusion, but is noted in case any other observer has seen the star double."

A New Variable Star in Auriga.-By comparison of photographs taken with a $4 \cdot 4$-in. portrait lens towards the end of 1905, Mr. A. Stanley Williams detected a star of varying magnitude situated in Auriga, and he has since then accumulated sufïcient visual observations to establish the character of the light-curve (Monthly Notices, R.A.S., vol. 1xxviii., p. 483). The position of the star for 1900 is R.A. 5 h. $8 \mathrm{~m} .27 \mathrm{~s}$., decl. $+39^{\circ} 57 \cdot 5^{\prime}$. The discussion of the observations shows that the variation is of the Cepheid type, and the period $18.35_{3}$ days. The magnitude ranges from 10.04 at maximum to 10.79 at minimum, and the interval from minimum to maximum is $7 \cdot 0$ days.

\section{FUNDAMENTAL PROBLEMS OF PHILOSOPHY AND SCIENCE.}

$A$ JOINT session of the Aristotelian Society, the British Psychological Society, and the Mind Association was held in London on July $5^{-8}$. The aim of this session, which has now been held for several years, is to endeavour to bring together the actual workers in mental and neurological science and those engaged in purely philosophical research tor the discussion of fundamental problems. The subjects discussed included problems of mathematics and NO. 2542 , VOL. IOI physics, of physiology and biology, of practical psychology, and of pure metaphysics.

Lord Haldane presided at the opening meeting, when Prof. Alexander expounded a new philosophical theory of space and time. His theory is that there is one primitive entity, the matrix or stuff of existence, space-time, and that all forms of mind and matter are complications of it. In the discussion Prof. Whitehead criticised it from the point of view of mathematical physics, and Prof. Pringle-Pattison from that of philosophy.

Prof. Wildon Carr presided at the discussion of the symposium "Are Physical, Biological, and Psychological Categories Irreducible?" The contributors were Dr. J. S. Haldane, Prof. D'Arcy Thompson, Dr. Chalmers Mitchell, and Prof. L. T. Hobhouse. The discussion proved of exceptional interest in the number of illustrations from applied science which were brought to bear on the question. The main problem was the adequacy of mechanistic interpretation as used in physics when applied to the higher spheres of life and mind. The opposing views were represented by Dr. Haldane and Prof. D'Arcy Thompson. Prof. Whitehead, Prof. Nicholson, and $\mathrm{Mr}$. Brierley contributed valuable accounts of experiments in their respective sciences, and Dr. Schiller, Lord Haldane, and others discussed the relation of the problem to philosophy.

Dr. C. S. Myers presided at the symposium "Why is "the Unconscious' Unconscious?" by Dr. Maurice Nicoll, Dr. W. H. R. Rivers, and Dr. Ernest Jones. The discussion was notable as emphasising a distinct change which seems to be manifesting itself in the theory and practice of psychoanalysis. Many of the distinctive features of Freud's original statement, e.g. the endo-psychic censor, seem to be vanishing into the background. There was remarkable unanimity in most of the speakers in regarding "the unconscious" as not simply a force resisting inhibition and baneful in its effect, but as essentially and primarily a force to be identified with the spring of life itself. Besides the three contributors to the svmposium, the chairman and Dr. McDougall, Dr. Mitchell, Dr. Crighton Miller, Dr. Constance Long, Dr. Goldsbrough, Mr. Flugel, and Prof. Wildon Carr took part.

The largest attendance was at the meeting on Sunday afternoon, when Mr. A. J. Balfour presided at the discussion of the symposium "Do Finite Individuals Possess a Substantive or an Adjectival Mode of Being?" The contributors were Prof. Bernard Bosanquet, Prof. Pringle-Pattison, Prof. G. F. Stout, and Lord Haldane. In the discussion Prof. Bosanquet defended with noticeable earnestness the view which is identified with the philosophy of $\mathrm{Mr}$. Bradley and himself, the view that the ultimate subject of predication is one and universal, that reality is the absolute. He was opposed by Prof. Pringle-Pattison, who acknowledged, however, a wide ground of common agreement. A more decided opposition came from Prof. Alexander. Lord Haldane, in a very clear summary of the two views, held that the real crux of the problem lay in the antithesis between the concepts of substance and subject, and suggested that the solution is the doctrine of degrees of truth and reality. Prof. Whitehead expressed the point in dispute with mathematical precision in his question addressed to all the disputants, "Is there any substantive existence of a relatum which is independent of all or any relation?"

The final meeting was presided over by Prof. Wildon Carr. "Two short communications, the first on "The Philosophical Importance of the Verb 'To Be,", by Miss L. S. Stebbing, the second on "The Summation of Pleasures," by Miss Dorothy Wrinch, both called forth an animated and interesting discussion. 